\title{
Influence of precipitation on the development of cube texture in $\mathrm{Al}-\mathrm{Mn}$ alloy*.
}

UDC $669.715^{\prime} 74: 548.53: 621.785 .7$

\section{Cong Danh NGUYEN**, Takeshi MURAKAMI*** and Tsuneo TAKAHASHI***}

Development of cube texture during final annealing in $\mathrm{Al}-1.1 \% \mathrm{Mn}$ alloy containing manganese as in solid solution and as a precipitate phase after partial recrystallization and moderate deformation was investigated by optical and electron microscopy, and X-ray diffraction. The frequency of formation of cube grain at partial recrystallization stage plays an important role because of the preferential growth of cube grain by strain induced boundary migration. In this case, sharp cube texture shows a spread of orientation around $\langle 100\rangle$ axis parallel to the rolling direction. Precipitation of $\mathrm{Al}_{6} \mathrm{Mn}$ prior to final annealing results in formation of retained rolling texture and the development of cube texture is suppressed.

(Received June 3, 1978)

\section{Introduction}

Recrystallization of Al-Mn alloy have been extensively studied ${ }^{1) \sim 3)}$. From an industrial point, the interest is centered on the contained manganese as in solid solution or as precipitate phase which influence recrystallization temperature and grain size ${ }^{3)-8}$. Most of works on the problem have been undertaken to investigate the precipitation phenomenon during recrystallization of supersaturated and deformed $\mathrm{Al}-\mathrm{Mn}$ alloy ${ }^{3), 6), 8}$. However, the effect of precipitation occuring during homogenization and hot rolling on the formation of recrystallization texture, in particular, of cube texture is little known ${ }^{9)}$.

In the preceding work on high purity aluminum ${ }^{10}$, a small amount of cube grains formed by means of partial recrystallization grow preferentially by strain induced boundary migration ${ }^{11)}$ at subsequent additional rolling and final annealing, and sharper cube texture is formed in comparison with that from usual process. Furthermore, sharp cube texture obtained by using the above method is effective to decrease $45^{\circ}$ earing of cup drawn from super hard sheet of $3004 \mathrm{Al}-\mathrm{Mn}-\mathrm{Mg}$ alloy ${ }^{12}$.

The present work was undertaken to examine the way in which partial recrystallization treatment effectively influences the formation of cube texture in $\mathrm{Al}-1.1 \% \mathrm{Mn}$ alloy.

\section{Experimental procedure}

The alloy, made of $99.99 \%$ purity aluminum and $\mathrm{Al}-9.95 \% \mathrm{Mn}$ master alloy was melted in a graphite crucible and cast into a steel mold. The chemical analysis of the alloy is shown in Table 1. The ingots

Table 1 Chemical composition of $\mathrm{Al}-1.1 \% \mathrm{Mn}$ alloy (wt $\%$ ).

\begin{tabular}{c|c|c|c|c}
\hline \hline $\mathrm{Mn}$ & $\mathrm{Fe}$ & $\mathrm{Si}$ & $\mathrm{Cu}$ & $\mathrm{Al}$ \\
\hline 1.08 & 0.03 & $<0.01$ & $<0.01$ & bal. \\
\hline
\end{tabular}

* Presented at the 54th conference of the Japan Institute of Light Metals.

** Graduate School of Tokyo Institute of Technology (Tokyo).

*** Tokyo Institute of Technology (Tokyo). 
were homogenized at $635^{\circ} \mathrm{C}$ for $48 \mathrm{hr}$ and hot-rolled to sheets $5 \mathrm{~mm}$ thickness. To retain manganese in solid solution, the sheets were treated at $640^{\circ} \mathrm{C}$ for $48 \mathrm{hr}$ and water quenched. After $90 \%$ cold rolling, the sheets were subjected to two annealing treatment involving a comparatively low $\left(320^{\circ} \mathrm{C}\right)$ and high temperatures $\left(430^{\circ} \mathrm{C}\right)$ to cause change in recrystallization and precipitation behaviors. The selection of these temperatures was based on the works by Nagahama et $a .^{3}{ }^{3}$. and Goel et al. ${ }^{6}$. During annealing treatment at $320^{\circ} \mathrm{C}$, fine dispersion of precipitates was formed before recrystallization occured. On the other hand, at $430^{\circ} \mathrm{C}$ recrystallization finished before precipitation took place, and manganese could be expected to be in solid solution.

The specimens for X-ray examination and microscopy were treated in following way.

Cold rolled sheet $\rightarrow$ Partial recrystallization $\rightarrow$ Additional cold rolling $\rightarrow$ Final annealing
$0.5 \mathrm{~mm}$ thickness
$320,430^{\circ} \mathrm{C}$
$0 \sim 30 \%$
$400^{\circ} \mathrm{C}$

Recrystallization texture, in particular, cube texture was recorded of all specimens finally annealed by transmission Laue photograph. All specimens were etched to a thickness of the specimen which was additionally rolled to $30 \%$ reduction. X-ray beam was kept to be perpendicular to rolling plane while specimen was given a vibration of $10 \mathrm{~mm}$ width. The sharpness of cube texture was determined by concentration of Laue spots which have a 4 fold symmetry to rolling plane normal. Orientation of large grains in specimen partially annealed at $320^{\circ} \mathrm{C}$ was determined by micro Laue camera method. $\{111\}$ pole figures were also determined by using diffractometer. Deformed and recrystallization structure of specimens made from each stage of the procedure were investigated by transmission electron microscopic observation.

\section{Results}

\subsection{Recrystallization characteristics at 320 and $430^{\circ} \mathrm{C}$}

Isothermal annealing curves for $\mathrm{Al}-1.1 \% \mathrm{Mn}$ sheets $90 \%$ rolled are shown in Fig. 1. Complete recrystallization is not yet achieved at $320^{\circ} \mathrm{C}$ even for 4 months. The slow softening is due to precipitates formed during annealing which inhibit dislocation rearrangement and migration of grain boundary for recrystallization. At such a low temperature continuous (in situ) recrystallization is only found ${ }^{6}$, and dense precipitate structure and retained rolling texture are expected to be formed ${ }^{8)}$. On the other hand, at $430^{\circ} \mathrm{C}$ the sheet fully recrystallized for about $1 \mathrm{~min}$ and manganese is estimated to be in solid solution.

\subsection{Formation of cube texture after final annealing}

Annealing treatment at 320 and $430^{\circ} \mathrm{C}$ were interrupted at various times, subsequently a small amount of reduction up to $30 \%$ was given and finally each specimen was annealed at $400^{\circ} \mathrm{C}$ for $6 \mathrm{hr}$. Such partial annealing and light rolling are to sharpen cube texture ${ }^{10), 12}$. Accordingly, two series of

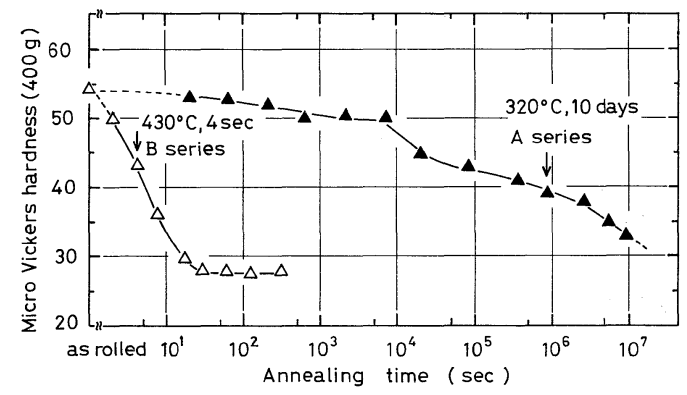

Fig. 1 Isothermal annealing curves at 320 and $430^{\circ} \mathrm{C}$ for $90 \%$ cold rolled sheet. 
specimens were prepared by selecting different annealing temperatures and annealing times, i.e. $320^{\circ} \mathrm{C}$ 10 days (namely A series) and $430^{\circ} \mathrm{C}, 4 \mathrm{sec}$ (namely B series). At $320^{\circ} \mathrm{C}$, since optical microstructure did not show clear boundary between deformation structure and recrystallized grain, partial annealing time was determined as that required for a half decrease of the hardness of the sheet as rolled. At $430^{\circ} \mathrm{C}$, it was the time for about 40 percent recrystallized, which was determined by optical microscopy. Microstructures of these specimens are shown in Photo 1. Dispersion of precipitates in the specimen held at $320^{\circ} \mathrm{C}$ for 10 days is shown in Photo 2. Precipitate particles with an average size about $0.5 \mu \mathrm{m}$ is formed

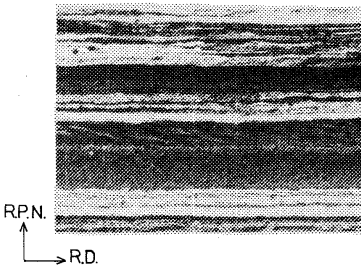

(a) $320^{\circ} \mathrm{C}, 10$ days

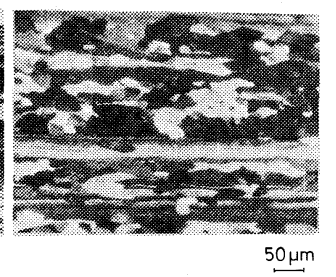

(b) $430^{\circ} \mathrm{C}, 4 \mathrm{sec}$

Photo 1 Optical micrographs of sheets annealed (a) at $320^{\circ} \mathrm{C}$ for 10 days and (b) at $430^{\circ} \mathrm{C}$ for $4 \mathrm{sec}$.

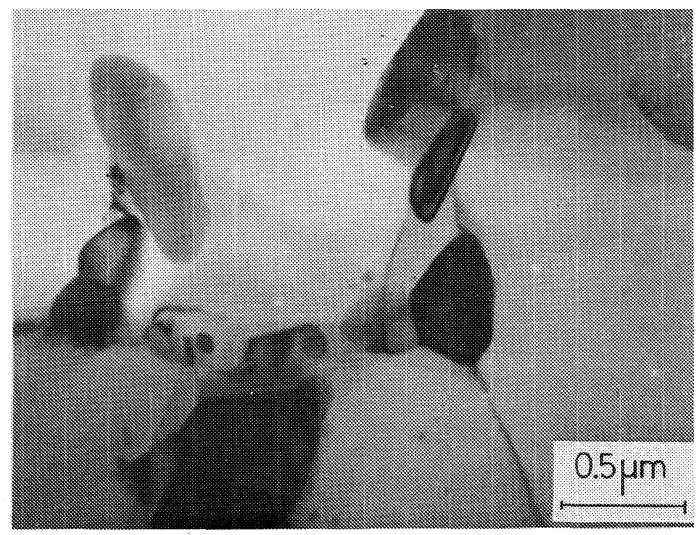

Photo 2 Electron micrograph of sheet annealed at $320^{\circ} \mathrm{C}$ for 10 days.

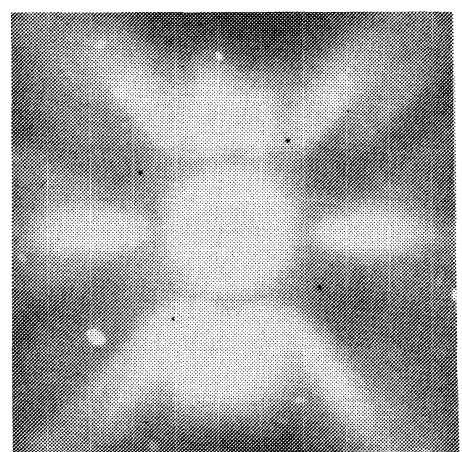

(a) rolling reduction $0 \%$

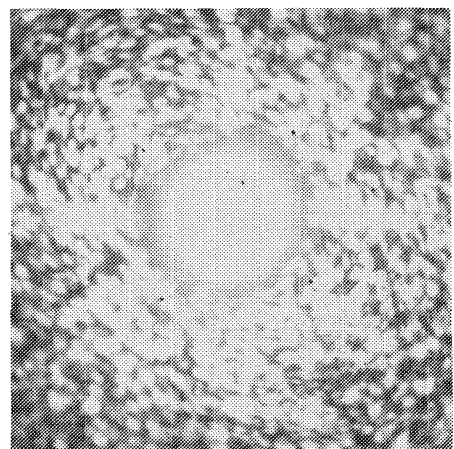

(d) $15 \%$

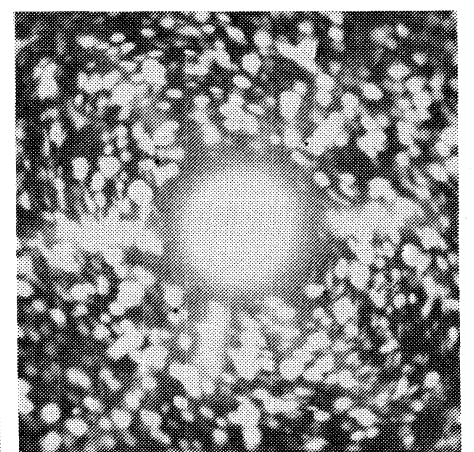

(b) $5 \%$

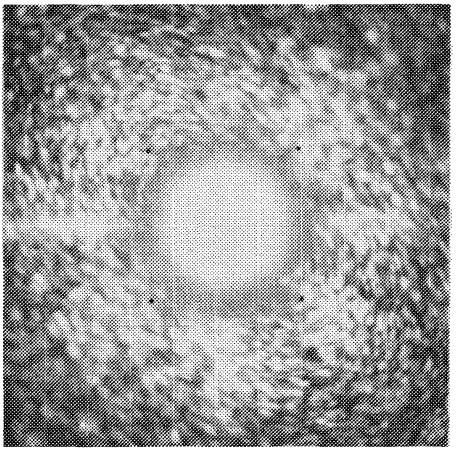

(e) $20 \%$

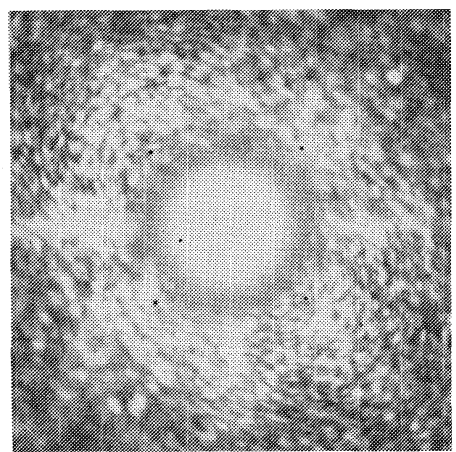

(c) $10 \%$

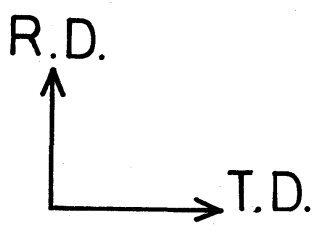

Photo 3 Transmission Laue photographs showing the sharpness of cube texture after annealing at $400^{\circ} \mathrm{C}$ for $6 \mathrm{hr}$ in A series correspondent with additional rolling reduction. 
at sub-boundaries, and smaller precipitates in the range 0.01 to $0.05 \mu \mathrm{m}$ are scattered in subgrains. Electron diffraction pattern shows that these particles are equilibrium phase $\mathrm{Al}_{\mathbf{6}} \mathbf{M n}^{\mathbf{1 3})}$.

Transmission Laue photographs presenting the sharpness of cube texture after final annealing are shown in Photos 3 and 4. It is clear that specimens made from B series show a remarkable development of cube texture in the 15-20\% reduction range while none of specimens from A series contains sharp cube texture. Specimen shown in Photo 3-(a) is not fully recrystallized, however, after long time of annealing weak cube texture is obtained. It is noticeable that a relatively random orientations are observed in the case of specimens in A series. Laue spots also imply that A series have an abnormally large grain size, the other side, a reverse result is obtained in B series. By using micro Laue camera, the orientations of these large grains were determined and these indicated that except a few cube grain existed the greater part distributed randomly. Since experiments on other partial recrystallization conditions did not show considerable change in the sharpness of cube texture, their results were not mentioned here.

$\{111\}$ pole figure for specimen in B series with $20 \%$ reduction which presented the most sharp cube texture is shown in Fig. 2. The recrystallization texture consists mainly of cube orientation. In particular, a spread of cube orientation about $\langle 100\rangle$ axis parallel to rolling direction is found. The formation of this spread can be explained as $\mathrm{Tucker}^{14)}$ and Kamijo ${ }^{15)}$ had proposed. By regarding deformation during rolling as a biaxial stress system and supposing slip systems having the maximum resolved shear stress are operating systems, it is thought that cube grain formed at partial annealing stage rotated around $\langle 100\rangle$ axis parallel to rolling direction during light rolling, consequently the spread might be

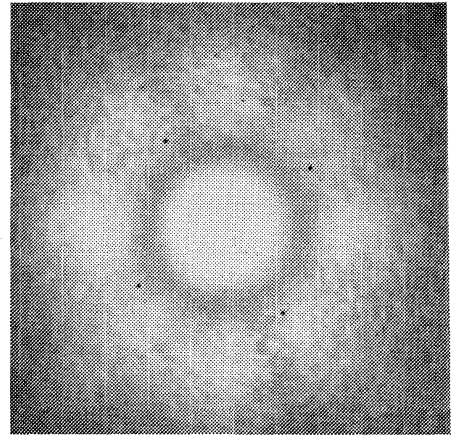

(a) rolling reduction $0 \%$

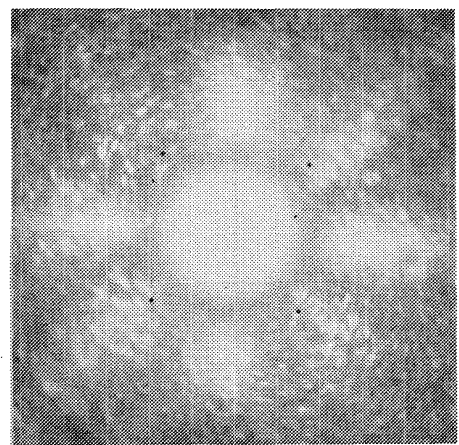

(d) $15 \%$

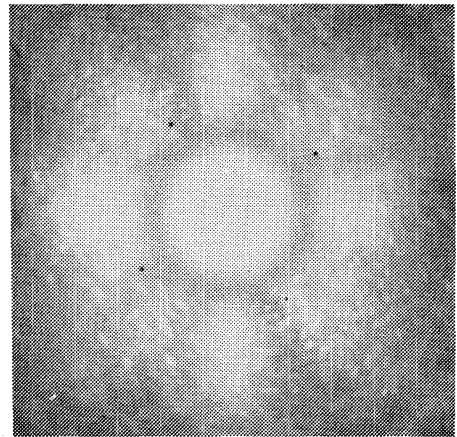

(b) $5 \%$

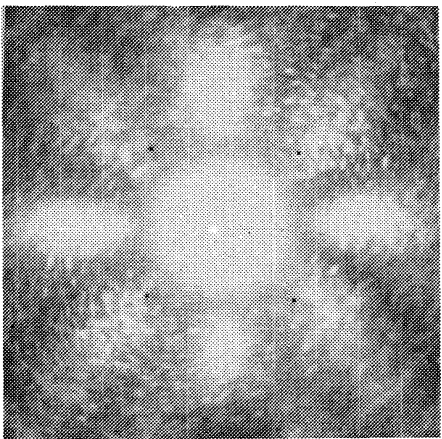

(e) $20 \%$

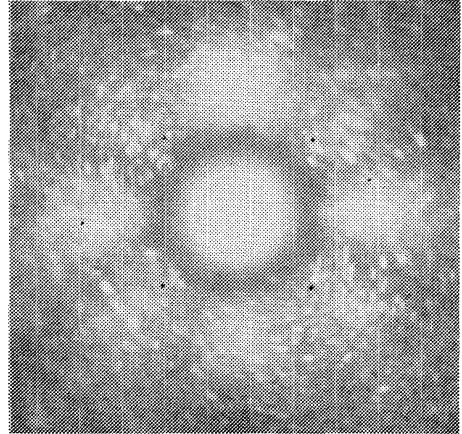

(c) $10 \%$

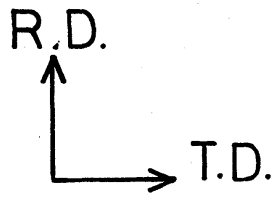

Photo 4 Transmission Laue photographs showing the sharpness of cube texture after annealing at $400^{\circ} \mathrm{C}$ for $6 \mathrm{hr}$ in $\mathrm{B}$ series correspondent with additional rolling reduction. 
retained even after final annealing.

\subsection{Transmission electron microscopic observation}

By selected area diffraction, a few cube orientation is only found in specimen partially recrystallized at $320^{\circ} \mathrm{C}$ for 10 days (A series). As shown in the $\{111\}$ pole figure, Fig. 3, for specimen annealed for 4 months at $320^{\circ} \mathrm{C}$, the texture consists of retained rolling texture with component near (123) [412] ]. These facts imply that at such low temperature, recrystallization in situ occurs and cube oriented grain is difficult to form.

On the other hand, electron micrographs for specimen showing sharp cube texture from B series after 20\% additional rolling shown in Photo 5 indicate some things which are remarkably contrast with specimens from A series mentioned above. A great difference in dislocation distribution between cube grain and other oriented grain exists (Photo 5-(a) and 5-(b)) and it should be emphasized that grain boundary (Photo 5-(c)) and cube grain are still remained even after 20\% rolling (Photo 5-(a) and 5 -(c)). At the first stage of final annealing $\left(400^{\circ} \mathrm{C}, 2 \mathrm{~min}\right)$ cube oriented subgrain with less dislocation

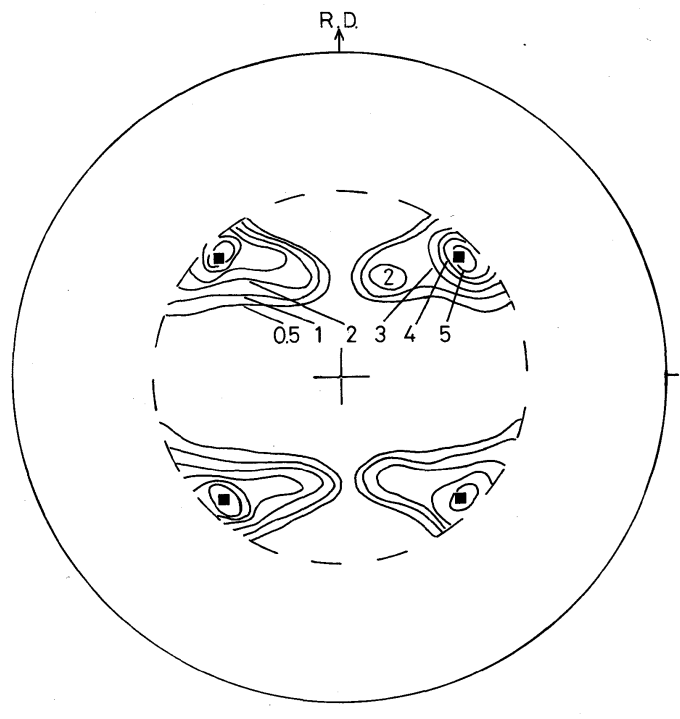

Fig. $2\{111\}$ pole figure showing the sharpness of cube texture for specimen annealed at $400^{\circ} \mathrm{C}$ for $6 \mathrm{hr}$ after partial annealing at $430^{\circ} \mathrm{C}$ for $4 \mathrm{sec}$ and additional rolling of $20 \%$ reduction. (100) [001]

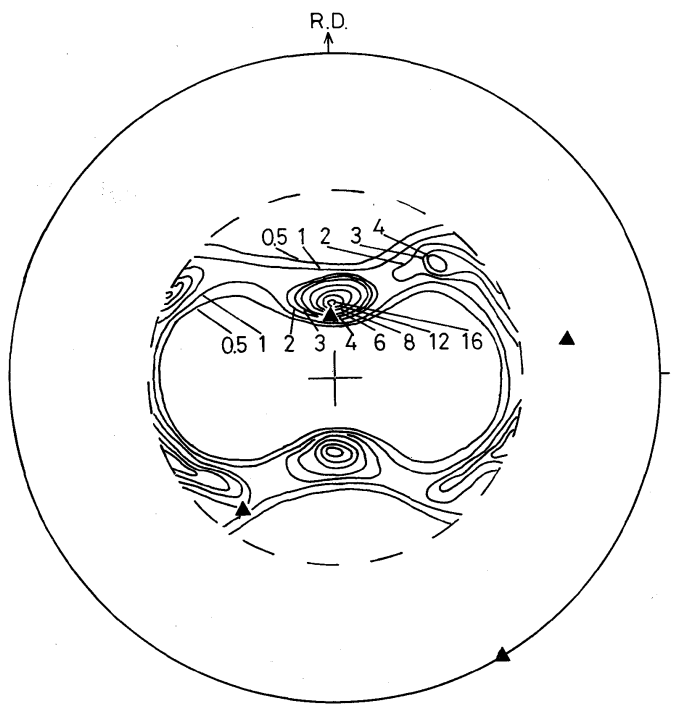

Fig. $3\{111\}$ pole figure showing retained rolling texture for $90 \%$ cold rolled sheet after annealing at $320^{\circ} \mathrm{C}$ for 4 months. $\Delta(123)[41 \overline{2}]$

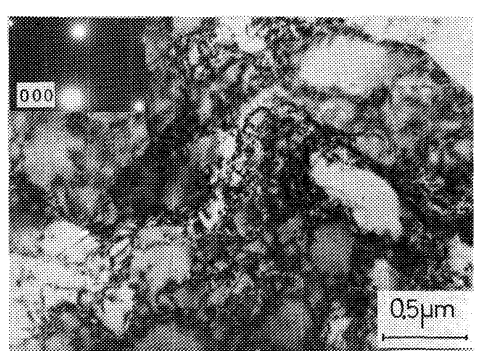

(a) cube grain
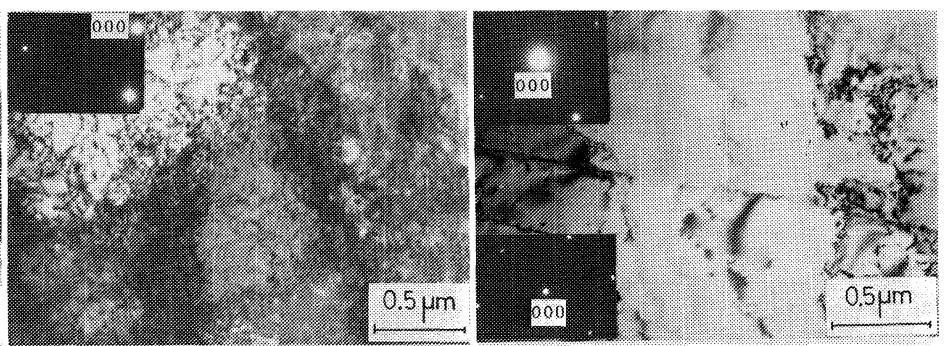

(b) non-cube grain (c) straight boundary dividing cube grain and non-cube grain

Photo 5 Electron micrographs of specimen in B series after partial annealing at $430^{\circ} \mathrm{C}$ for 4 sec and additional rolling of $20 \%$ reduction showing difference of dislocation distribution in cube grain and non-cube grain. 
density seemed to grow preferentially into surroundings as shown in Photo 6. Furthermore, after $6 \mathrm{hr}$ of annealing, cube grain with curved boundary migrating towards neighbouring grain (Photo 7) is often observed.

\section{Discussion}

In general, the recrystallization texture of $\mathrm{Al}-\mathrm{Mn}$ alloy sheet consists of mainly (100)[001] orientation $^{9)}$, however, the intensity of cube orientation is not a high one in comparison with that obtained as shown in Fig. 3. This fact indicates that the process used in the present work is effective to develop cube texture. Direct electron microscopic evidence of the migration of cube grain boundary is not yet achieved because of the relatively high final annealing temperature. However, since there are a large amount of cube grain and particularly, great difference in dislocation density (or strain energy) between cube and other oriented grain prior to annealing (Photo 5), and the evidences from Photos 6 and 7 can be used as an example for the preferential growth of cube grain, it could be concluded that the formation of sharp cube texture in B series is due to the predominant growth of cube oriented grain. That is, cube grains grow preferentially after additional rolling and subsequent annealing by the phenomenon ${ }^{10)}$ which is similar to strain induced boundary migration reported by Beck and Sperry ${ }^{11}$.

Of the two conditions examined, less cube texture is found in specimens of A series. The weak development of cube texture can be due to two causes: a) the presence of R-orientation in the matrix formed by recrystallization in situ during partial recrystallization at $320^{\circ} \mathrm{C}$ or b) the existence of $\mathrm{Al}_{6} \mathrm{Mn}$ precipitates at subgrain boundaries. Considering nucleation of cube oriented grain can not occur in retained R-orientation matrix by lattice rotation during light rolling, it is improper to consider that large quantity of cube grain could be generated from the matrix during final annealing. In this case, it is therefore inferred that a few amount of cube grain and a greater part of R-orientated grain could be formed.

If sub-boundaries are preferential sites for precipitation of $\mathrm{Al}_{6} \mathrm{Mn}$, it is thought that formation of cube texture will be more delayed than formation of retained rolling texture by such precipitation. This explanation is consistent with the result in Photo 3 and $\{111\}$ pole figure determined by micro

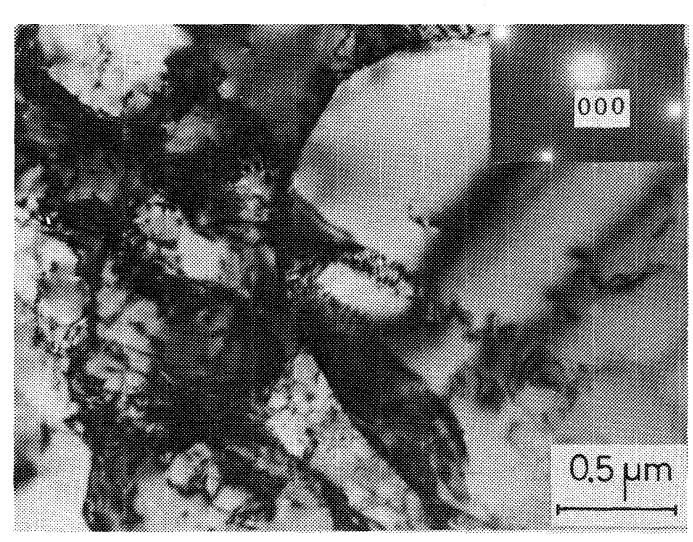

Photo 6 Electron micrograph of specimen in B series annealed at $400^{\circ} \mathrm{C}$ for 2 min after partial annealing at $430^{\circ} \mathrm{C}$ for $4 \mathrm{sec}$ and additional rolling of $20 \%$ reduction. Diffraction pattern was taken from the sub-grain at the right hand side of the photograph.

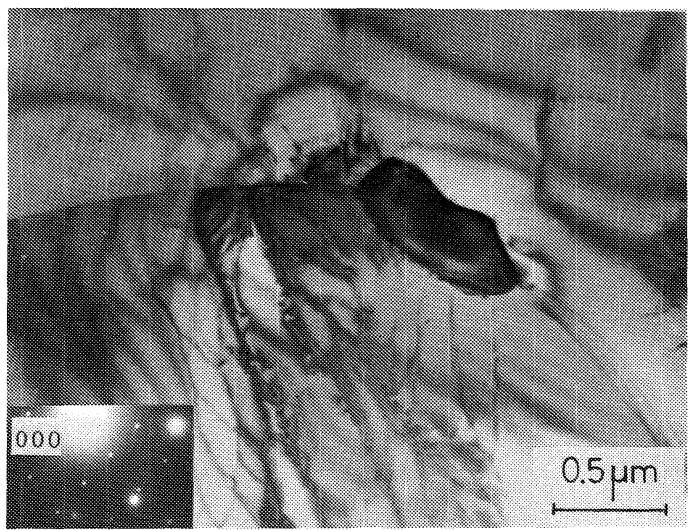

Photo 7 Electron micrograph of specimen in B series annealed at $400^{\circ} \mathrm{C}$ for $6 \mathrm{hr}$ after partial annealing at $430^{\circ} \mathrm{C}$ for $4 \mathrm{sec}$ and additional rolling of $20 \%$ reduction. 
Laue camera.

\section{Summary}

1. Cube texture develops considerably during final annealing in $\mathrm{Al}-1.1 \% \mathrm{Mn}$ alloy after rolling of $90 \%$ reduction, partial annealing at temperature which leads to recrystallization preceding precipitation, and light rolling. This is mainly due to the preferential growth of cube grain by strain induced grain boundary migration.

2. In this case, it is characteristic that sharp cube texture shows a spread of orientation around $\{100\}$ axis parallel to rolling direction.

3. Partial recrystallization treatment at low temperature generates precipitation of $\mathrm{Al}_{6} \mathrm{Mn}$ at subboundaries and recrystallization in situ, accordingly development of cube texture is suppressed.

\section{References}

1) P. A. Beck, M. L. Holzworth and P. R. Sperry: Trans. AIME, 180 (1949), 163.

2) F. Gatto, G. Camona and M. Conserva: Mater. Sci. Eng., 3 (1968-1969), 56.

3) K. Nagahama, M. Takahashi and I. Miki: J. Japan Inst. Light Metals, 21 (1971), 444.

4) P. R. Sperry: Trans. A.S.M., 50 (1958), 589.

5) W. G. Setzer and J. G. Morris: Trans. A.SM., 57 (1964), 589.

6) D. B. Goel, P. Furrer and H. Warlimont: Aluminium, 50 (1974), 641.

7) E. Nes and J. D. Embury: Aluminium, 66 (1975), 589.

8) P. Furrer and H. Warlimont: Aluminium, 54 (1978), 135.

9) R. Rixen, R. Musik, H. Göker and K. Lücke: Z. Metallkde., 66 (1975), 16.

10) T. Murakami, C. D. Nguyen and T. Takahashi: J. Japan Inst. Light Metals, 28 (1978), 267.

11) P. A. Beck and P. R. Sperry: J. Appl. Phys., 21 (1950), 150.

12) T. Takahashi, T. Murakami and C. D. Nguyen: J. Japan Inst. Light Metals, 28 (1978), 35.

13) A. D. I. Nicol: Acta Cryst., 6 (1953), 285.

14) G. E. G. Tucker: Acta Met., 12 (1964), 1093.

15) T. Kamijo: J. Japan Inst. Met., 30 (1966), 207. 